\title{
Análise crítica do discurso multimodal de representações das mulheres em anúncios de cerveja: multiletramentos em sala de aula
}

\author{
Multimodal critical discourse analysis of \\ representations of women in beer ads: \\ multiliteracies in the classroom
}

\author{
Maria Vanessa Monteiro das Chagas \\ Universidade Federal da Paraíba, João Pessoa, Paraíba, Brasil \\ Fábio Alexandre Silva Bezerra \\ Universidade Federal da Paraíba, João Pessoa, Paraíba, Brasil
}

Resumo: Este artigo objetiva refletir sobre a leitura do gênero anúncio em sala de aula, sob uma perspectiva crítica, e evidenciar o potencial do trabalho com textos que refletem posicionamentos ideológicos que marcam questões sociais complexas. Para tal, evidenciamos a relevância do trabalho com este gênero amparado por importantes documentos oficiais (BRASIL, 1998, 2006, 2018). Além disso, recorremos aos estudos da Análise Crítica do Discurso (FAIRCLOUGH, 2015[1989], 2001; MEURER, 2005) para discutir questões que envolvem discursos e ideologias que perpassam os textos analisados, bem como utilizamos conceitos e categorias de análise da gramática do design visual (KRESS; VAN LEEUWEN, 2006), transpostos de maneira mais didática, em língua portuguesa, por Nascimento, Bezerra e Heberle (2011) com vistas ao desenvolvimento de práticas de multiletramentos no contexto escolar, para nortear a análise dos recursos multimodais que compõem os anúncios analisados, a partir dos quais discutimos reconfigurações de representações das mulheres em anúncios de cerveja. Resultados gerais indicam que, apesar de avanços nas representações de gênero nos anúncios analisados, outras questões mais interseccionais (AKOTIRENE, 2019; COLLINS; BILGE, 2016), tais como raça, etnia, classe e sexualidade são completamente negligenciadas, apontando para a urgência dessa problematização também no contexto escolar.

Palavras-chave: Análise Crítica do Discurso; Gramática do Design Visual; Mulheres; Anúncios de Cerveja; Sala de Aula

\begin{abstract}
This article aims to reflect on the reading of genre 'advertisement' in the classroom, from a critical perspective, and to highlight the potential of working with texts that reflect ideological positions underscoring complex social issues. To this end, we stress the relevance of working with this genre
\end{abstract}

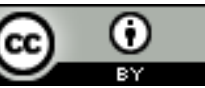


supported by important official documents (BRASIL, 1998, 2006, 2018). Additionally, we refer to studies in Critical Discourse Analysis (FAIRCLOUGH, 2015 [1989], 2001; MEURER, 2005) to discuss issues involving discourses and ideologies that permeate the texts analyzed, and also use concepts and categories of analysis of the grammar of the visual design (KRESS; VAN LEEUWEN, 2006), translated in a more didactic way to Portuguese by Nascimento, Bezerra and Heberle (2011) with a view to the development of multiliteracy practices in the school context, to guide the analysis of the multimodal resources that make up the ads analyzed, from which we discuss reconfigurations of representations of women in beer ads. General results indicate that, despite advances in gender representations in the ads analyzed, other more intersectional issues (AKOTIRENE, 2019; COLLINS; BILGE, 2016), such as race, ethnicity, class and sexuality are completely neglected, pointing to the urgency of this problematization also in the school context.

Keywords: Critical Discourse Analysis; Grammar of Visual Design; Women; Beer Ads; Classroom

\section{Introdução}

Em uma sociedade letrada, a prática da leitura possui uma notável importância, dada a intensa frequência com que somos expostos a textos pertencentes aos mais diferentes gêneros, ${ }^{1}$ dentre os quais destacamos os anúncios devido a sua larga presença nos mais diversos suportes: revistas, outdoors, cartazes, panfletos, jornais, redes sociais, etc. Para além desses espaços, o anúncio também tem ocupado espaço privilegiado na sala de aula, pois, além de ser frequentemente visto em livros didáticos, há diretrizes para um tratamento sistemático e reflexivo desse gênero em documentos oficiais como os Parâmetros Curriculares Nacionais - PCN (BRASIL, 1998), as Orientações Curriculares para o Ensino Médio - OCEM (BRASIL, 2006), e a Base Nacional Comum Curricular BNCC (BRASIL, 2018). De maneira geral, esses documentos oficiais postulam que é papel da escola sistematizar o ensino de leitura, proporcionando um aprendizado contextualizado e promovendo letramentos múltiplos, que se referem ao trabalho com a linguagem em situações reais de comunicação a partir da ênfase nas multiplicidades de recursos semióticos e de culturas (ROJO, 2009).

\footnotetext{
${ }^{1}$ Entendidos, aqui, como um "conjunto de convenções relativamente estável que é associado com, e parcialmente realiza, um tipo de atividade socialmente aprovado" (FAIRCLOUGH, 2001, p. 161).
} 
Essa inserção crítica implica a reflexão e a problematização do que é lido, tendo em vista a relevância da compreensão sobre a relação bidirecional existente entre discurso e estruturas sociais (MEURER, 2005) para o desenvolvimento de práticas de multiletramentos que favoreçam discussões de textos das diversas mídias e culturas, de maneira situada e reflexiva. Dessa maneira, espera-se que os/as alunos/as tenham maiores possibilidades de conseguir questionar as finalidades, concepções e ideologias que perpassam as manifestações linguísticas na sociedade contemporânea (BEZERRA, 2016).

Nesse sentido, objetivamos, nesta investigação, de natureza qualitativa e de caráter interpretativista, propor a reflexão sobre a leitura do gênero anúncio em sala de aula sob uma perspectiva crítica, bem como evidenciar o potencial emancipatório do trabalho com textos a partir da análise e da discussão dos aspectos linguísticos, ideológicos e culturais que os perpassam. Para tanto, valemo-nos de conceitos propostos pela Análise Crítica do Discurso (ACD), mais especificamente no modelo tridimensional de Fairclough (2015[1989]). Além disso, utilizamos conceitos e categorias de análise da gramática do design visual (GDV) de Kress e Van Leeuwen (2006), transpostos de maneira mais didática, em língua portuguesa, por Nascimento, Bezerra e Heberle (2011) com vistas ao desenvolvimento de práticas de multiletramentos no contexto escolar.

\section{O trabalho com textos para a leitura crítica}

Os documentos oficiais, como os PCN (BRASIL, 1998), orientam o desenvolvimento de um processo de ensino-aprendizagem em que sejam fornecidos meios para $o$ desenvolvimento uma postura proativa e crítica para a vida em sociedade. Em se tratando da disciplina de Língua Portuguesa, esse documento aponta que

é preciso que as situações escolares de ensino de Língua Portuguesa priorizem os textos que caracterizam os usos públicos da linguagem. Os textos a serem selecionados são aqueles que, por suas características e usos, podem favorecer a reflexão crítica, o exercício de formas de pensamento mais elaboradas e abstratas, bem como a fruição estética dos usos artísticos da linguagem, ou seja, os mais vitais para a plena participação na sociedade letrada. (BRASIL, 1998, p. 24) 
No que tange a seleção dos textos a serem lidos, Rojo (2009, p. 115) afirma que cabe à escola "potencializar o diálogo multicultural, trazendo para dentro de seus muros não somente a cultura valorizada, canônica, mas também as culturas locais e populares e as culturas de massa, para torná-las vozes de um diálogo, objeto de estudo e de crítica". Desse modo, enfatiza-se a pertinência do trabalho com textos que estão presentes no cotidiano dos alunos, mas que, justamente por fazerem parte das vivências diárias, tendem a ter seus discursos naturalizados pela frequência com que são reproduzidos e pela ausência de uma reflexão crítica sobre eles.

Focalizando um postura anti-hegemônica, a partir dos postulados de uma Linguística Aplicada indisciplinar (KLEIMAN, 2013; MOITA-LOPES, 2006), entendemos que a escola deve priorizar a busca por conhecer, questionar e propor mudanças em realidades sociais, bem como em nossas posturas individuais, constituindo lócus de formação para a vida, para a cidadania crítica e para a humanidade. Cabe ressaltar, ainda, que tal postura se coaduna com princípios basilares da $\mathrm{ACD}$, uma vez que esta objetiva, de maneira geral, "analisar, criticar e, finalmente, mudar a realidade social na qual o discurso se relaciona de modos particulares com outros elementos sociais, tais como relações de poder, ideologias, e estratégias políticas e econômicas" (FAIRCLOUGH, 2015[1989], p. 5, tradução nossa). ${ }^{2}$ Dessa maneira, entendendo a linguagem como prática social, devemos promover um ensino que possibilite práticas de multiletramentos que, para além do domínio do código linguístico, atentem para os diversos modos semióticos e significados culturais que imprimem riqueza e diversidade em diversas configurações textuais.

\section{BNCC, ACD e leitura de textos multimodais contemporâneos}

A atual conjuntura da sociedade exige que o trabalho com a linguagem seja pensado para além do ensino da leitura do texto escrito de maneira isolada e descontextualizada. Temse refletido, cada vez mais, sobre a necessidade de aproximar a escola do contexto real em que os/as alunos/as estão inseridos/as, permeado por gêneros multimodais que falam de suas experiências de vida em sociedade.

2 Todas as traduções feitas neste artigo são de nossa responsabilidade. 
Dessa maneira, cabe destacar o importante papel ocupado pelas tecnologias digitais de informação e comunicação (TDIC) em um cenário em que a imagem tem ganhado destaque em diversos âmbitos da tessitura social, a saber: redes sociais, jogos para smartphone, clipes musicais, vídeos em plataformas de streaming. Nesse contexto, os anúncios invadem as telas com suas cores e textos verbais e imagéticos para influenciar nossos padrões de consumo e, de maneira mais geral, nossos próprios comportamentos sociais.

Compreende-se, portanto, que os novos tempos pedem novas abordagens e metodologias para o trabalho com a leitura e a produção textual no contexto escolar a fim de desenvolver competências indispensáveis na sociedade contemporânea. Nesse sentido, a BNCC aponta, dentre elas, a importância de saber

\begin{abstract}
analisar formas contemporâneas de publicidade em contexto digital (advergame, anúncios em vídeos, social advertising, unboxing, narrativa mercadológica, entre outras), e peças de campanhas publicitárias e políticas (cartazes, folhetos, anúncios, propagandas em diferentes mídias, spots, jingles etc.), identificando valores e representações de situações, grupos e configurações sociais veiculadas, desconstruindo estereótipos, destacando estratégias de engajamento e viralização e explicando os mecanismos de persuasão utilizados e os efeitos de sentido provocados pelas escolhas feitas em termos de elementos e recursos linguístico-discursivos, imagéticos, sonoros, gestuais e espaciais, entre outros. (BRASIL, 2018, p. 522)
\end{abstract}

Pensar nos diferentes discursos que circulam na sociedade requer atenção para o fato de que estes estão revestidos de ideologias imbricadas em relações de poder (MEURER, 2005) a partir de complexas redes de relações de dominação com base na classe, no gênero social, no grupo cultural, e assim por diante (FAIRCLOUGH, 2001). Dessa maneira, as discussões possibilitadas por meio da articulação de conceitos propostos pela ACD se mostram pertinentes para a análise textual, uma vez que o discurso é analisado a partir de um modelo tridimensional (FAIRCLOUGH, 2015[1989]) que contempla texto, práticas discursivas e práticas sociais (Fig. 1). 


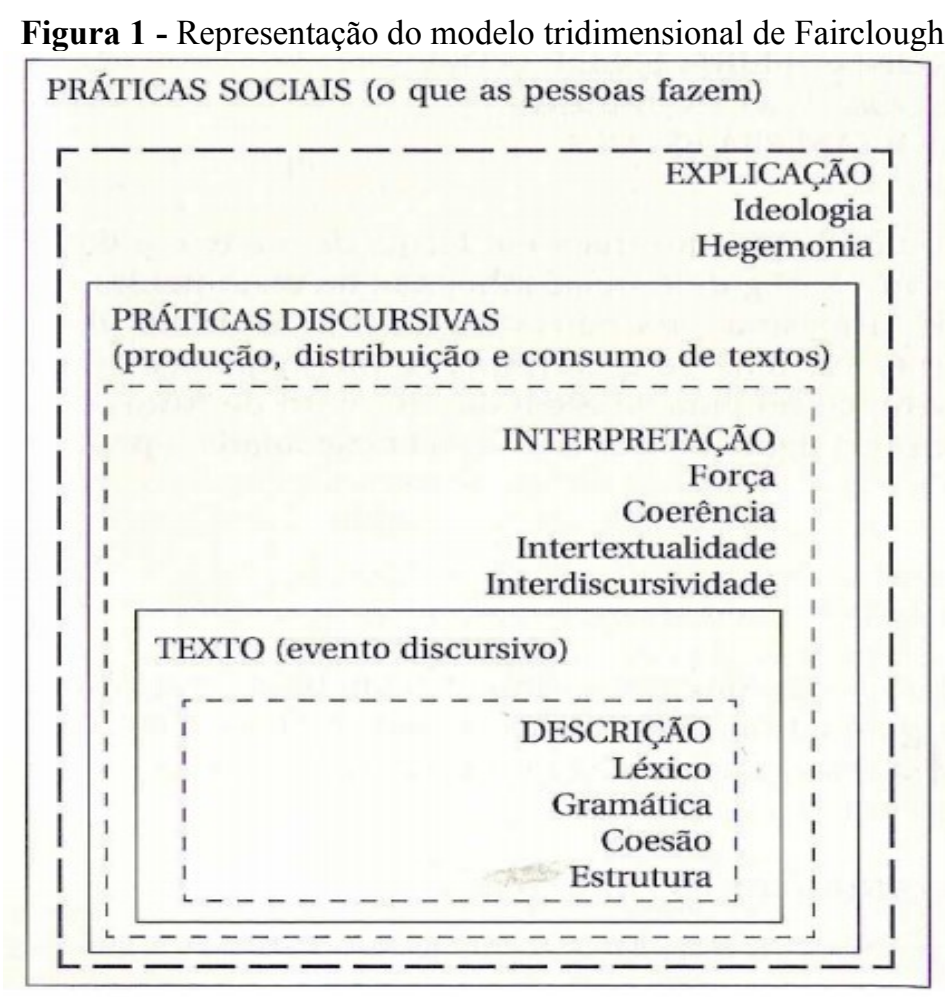

Fonte: Meurer (2005, p. 95)

Nesse modelo, a primeira dimensão (texto) privilegia a descrição de elementos linguísticos, tais como o léxico, as opções gramaticais e a estrutura, constituindo uma análise dos significados mais imediatos do texto. Já a dimensão das práticas discursivas contempla a interpretação do texto, levando em consideração questões relativas à produção, à distribuição e ao consumo, bem como sua força ilocucionária, coerência e relação com outros textos e discursos. Por fim, em relação às praticas sociais, entra em questão a explicação dos aspectos sociais relacionados a relações de poder, formações ideológicas e forças hegemônicas, atentando para questões sociais complexas, tais como: raça, etnia, classe, gênero, orientação sexual, questões de orientação política e econômica, etc.

Desse modo, reiteramos a visão da escola como um importante lócus de discussão e formação para a adoção de posturas proativas e críticas perante tais discursos, visando à adoção de uma atitude emancipatória, a partir da qual se estabelece a busca por conscientizar os indivíduos sobre a produção, a manutenção e a promoção de mudanças das relações de poder, a partir da percepção da existência e possibilidade de superação dos processos de naturalização de desigualdades. 
Tendo em vista que os dados de análise desta pesquisa são textos multimodais, e que "para a análise dos textos, devemos levar em consideração todos os modos semióticos, sendo necessário unir a questão da imagem e do texto verbal à questão social imbricada nas relações de poder existentes" (BONIFÁCIO, 2013, p. 220), buscamos estabelecer um diálogo entre a ACD e a GVD, cujos conceitos e categorias de análise são apresentados a seguir.

\section{A gramática do design visual: fundamentos para a análise de textos multimodais}

A gramática do design visual (KRESS; VAN LEEUWEN, 2006) se propõe a fornecer caminhos para uma análise sistemática de elementos visuais através de três sistemas (ou dimensões) de significados, nomeados metafunções, a saber: a representacional, a interativa e a composicional. A seguir, apresentaremos, de maneira sucinta, cada uma destas e suas respectivas subdivisões.

A metafunção representacional contempla as estruturas que constroem visualmente a natureza dos eventos a partir dos/as participantes representados/as. Esta metafunção subdivide-se em: narrativa, a partir da qual pode-se reconhecer processos de ação e reação, desempenhados por atores ou reagentes, e sinalizados por vetores que indicam a direcionalidade do movimento, bem como processos verbais e mentais; e conceitual, que trata da representação de personagens em termos de classe, estrutura ou significação, por meio de processos classificacionais, analíticos ou simbólicos.

Em representações narrativas, o processo de ação (p. ex. abraçar na Fig. 2) é indicado por um vetor que parte do participante (ator) em direção (ou não) a uma meta. Quando é reconhecível uma meta, trata-se de um processo transacional, que pode ser uni ou bidirecional. Nos casos em que o ator não direciona a ação a nada/ninguém, no escopo da imagem, estabelece-se um processo não-transacional.

Os processos de reação (p. ex. olhar o computador na Fig. 3), por sua vez, caracterizam-se pela presença de um vetor constituído pela linha do olhar que parte de um/a participante humano/a ou personificado/a (reagente), também podendo ser 
transacional ou não-transacional, caso a pessoa/coisa (fenômeno) objeto do olhar do/a participante esteja ou não representada no escopo da imagem.

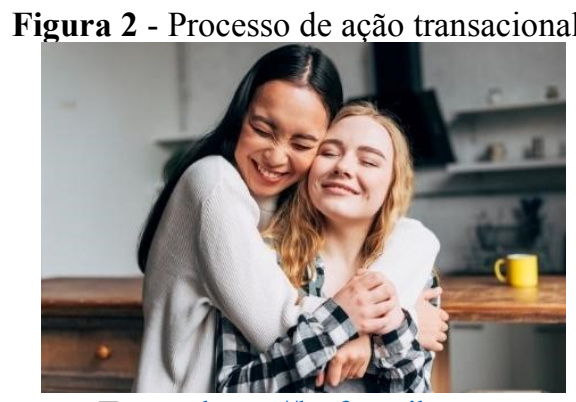

Fonte: https://br.freepik.com

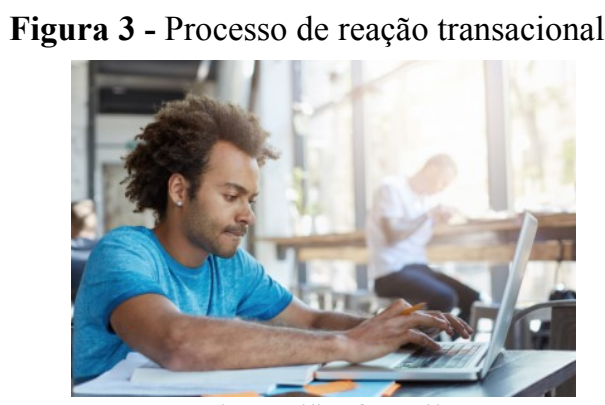

Fonte: https://br.freepik.com

Nas representações narrativas, pode, ainda, ocorrer outros dois tipos de processos, quais sejam os verbais ou os mentais, caracterizados por balões de fala ou de pensamento, que são conectados a um/a participante humano/a ou personificado/a, como podemos observar nas Figuras 4 e 5, respectivamente. Quando se referem a processos verbais, esses/as participantes são chamados/as de dizentes, sendo identificados como experienciadores/as quando se referem a processos mentais.

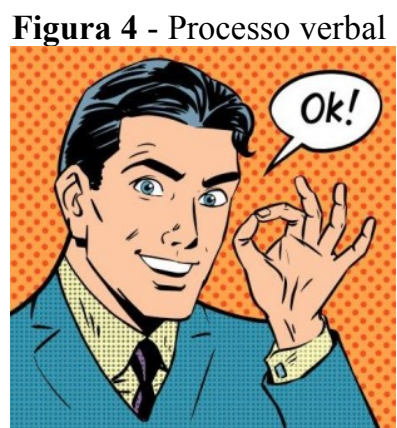

Fonte: https://br.depositphotos.com

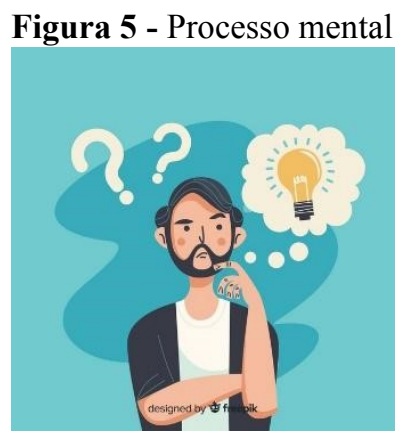

Fonte: $\underline{\text { https://br.freepik.com }}$

Nas representações conceituais, o foco está nos atributos dos/as participantes, analisados em termos de classe, estrutura ou significação, inseridos em processos que são realizados em situações mais estáticas, podendo ser identificados como classificatórios, analíticos ou simbólicos. Neste primeiro, há a representação de elementos que partilham características comuns (p. ex. frutas na Fig. 6), podendo constituir uma taxonomia explícita ou implícita.

Já os processos analíticos contemplam uma relação entre a parte e o todo, de modo que apenas um ou alguns elementos são retratados, produzindo determinados efeitos de 
sentido. Como é o caso da Figura 7, composta pela parte de um carro que contém painel e volante, indicando se tratar de um modelo antigo. Os processos simbólicos, por sua vez, caracterizam-se por atribuir ou sugerir sentidos diversos à imagem, num processo similar ao uso de metáforas ou simbologias na linguagem verbal (p. ex. martelo do juiz na Fig. $8)$.

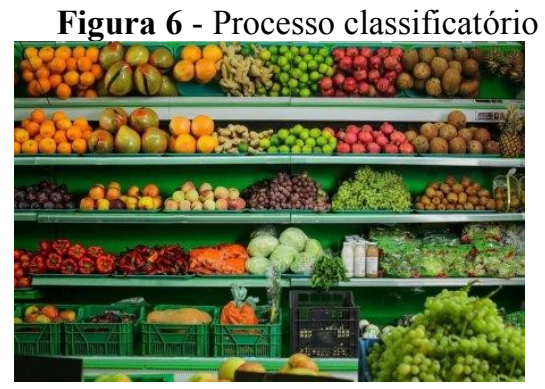

Fonte: https://br.depositphotos.com
Figura 7 - Processo analítico

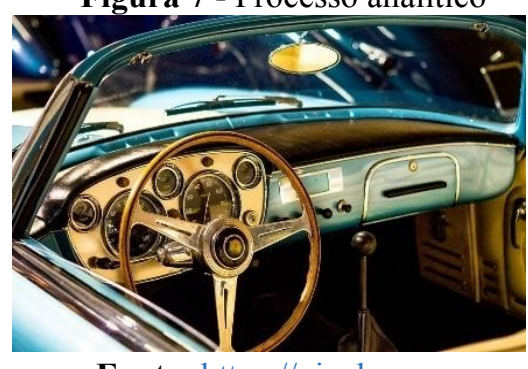

Fonte: https://pixabay.com

$\mathrm{Na}$ metafunção interativa, o foco está nas relações estabelecidas entre os/as participantes e o/a leitor/a, de modo que a análise dos elementos visuais contempla os seguintes aspectos: contato, distância social, atitude e poder. A categoria contato diz respeito à relação entre o/a participante e o/a leitor/a, que pode se dar de maneira pessoal, num contato de demanda em que o/a personagem olha diretamente para o/a leitor/a (Fig. 9), ou impessoal, configurando uma oferta, em que não há contato direto (Fig. 3).

Figura 8 - Processo simbólico

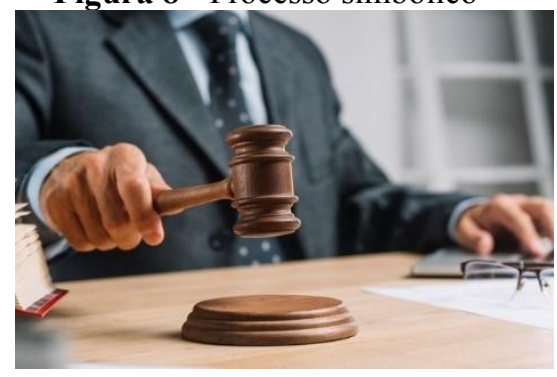

Fonte: https://br.freepik.com
Figura 9 - Contato: demanda

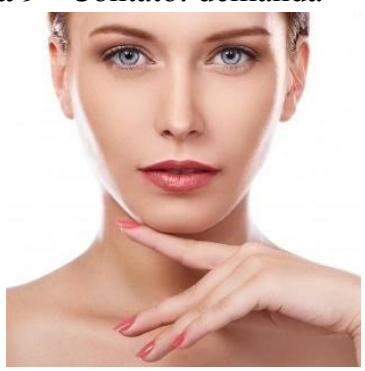

Fonte: $\underline{\text { https://br.freepik.com }}$

A distância social muda de acordo com variações no distanciamento da câmera, podendo constituir um plano fechado (close-up), como na Figura 9, a partir do qual é concebida uma relação de proximidade; plano médio (médium shot), em que um participante é representado, em média, da cintura pra cima (Fig. 5), marcando sociabilidade; ou plano aberto (long shot), em que se vê todo o corpo, conferindo maior 
grau de impessoalidade. Em relação à atitude, dá-se ênfase ao grau de envolvimento percebido a partir da angulação mais frontal (Fig. 5) ou oblíqua (Fig. 3) do/a participante em relação ao/à observador/a. Finalmente, no que tange ao poder, a opção pelo ângulo alto (Fig. 7), no nível do olhar (Fig. 2), ou baixo (Fig. 8), evidencia a relação de poder estabelecida entre participante e observador/a a partir dos diferentes ângulos da câmera.

A metafunção composicional integra os elementos das duas metafunções anteriores, fornecendo meios para uma análise pormenorizada da imagem a partir de três aspectos: valor de informação, enquadramento e saliência. Este primeiro diz respeito à disposição dos elementos, que podem estar na esquerda (informação dada) ou direita (informação nova), como na Figura 3; topo (elemento ideal) ou base (elemento real); e centro (elemento principal) ou margens (elementos secundários), como na Figura 2. Quanto ao enquadramento, os elementos podem estar visivelmente interligados (Fig. 3) ou separados (Fig. 6), sugerindo a existência ou não de conexão entre eles. Já a saliência revela o emprego de recursos como cores, tamanho relativo, foco e posicionamento ( $p$. ex. martelo do juiz na Fig. 8), sugerindo hierarquia entre os elementos que compõem o texto e interferem diretamente na leitura e interpretação deste.

A seguir, apresentamos uma proposta de análise do gênero anúncio, a partir da qual nos propomos a refletir sobre representações da mulher em anúncios de cerveja nas décadas de 50/60 e suas reconfigurações divulgadas no primeiro semestre de 2019. Além dos anúncios, há uma breve discussão sobre reportagens que circularam sobre essa atitude da marca a fim de inserir na análise algumas questões do macrocontexto.

\section{Oênero anúncio em sala de aula: uma proposta de análise}

No início do mês de março de 2019, nas proximidades da data em que se comemora o Dia Internacional da Mulher, a empresa Anheuser-Busch InBev, fabricante da cerveja Budweiser, em parceria com a campanha \#SeeHer, que objetiva melhorar as representações de mulheres na publicidade, recriou uma série de anúncios da década de 50 e 60 , hoje considerados sexistas, divulgando um comparativo entre estes e suas versões "atualizadas" para o novo contexto, criadas pelas ilustradoras Heather Landis, Nicole Evans e Dena Cooper. Esta atitude leva-nos a refletir sobre questões como: O que se 
espera com essa reformulação? Por que esta data em específico? O que essa reconfiguração nos diz sobre a nossa sociedade atual?

Antes de analisar as modificações feitas no anúncios originais, observemos os títulos e leads de algumas reportagens publicadas na semana em que os novos anúncios foram divulgados.

Figura 10 - Título e lead de reportagem da revista Exame

\section{Budweiser recria para 2019 seus anúncios machistas dos anos 50}

Marca americana refaz seus cartazes do passado e corrige histórico de machismo

Fonte: https://exame.abril.com.br

No primeiro exemplo, o escritor adjetiva os anúncios que foram recriados como "machistas" desde o título, marcando uma concepção sobre seu conteúdo e, em seguida, situa a época em que estes textos circularam. Enquanto no lead afirma-se que, com esta atitude a empresa corrige o histórico de machismo, podemos questionar esta concepção de que o novo posicionamento linguístico-ideológico da empresa teria o "poder" de corrigir quase que automaticamente um passado marcado pelo machismo, de modo que o foco estaria na melhoria da imagem da marca perante o público feminino e demais aliados, a fim de atraí-los e/ou (re)conquistá-los. Vejamos, a seguir, que há um enfoque diferente na reportagem publicada no site Huffpost.

Figura 11 - Título e lead de reportagem publicada no site Huffpost

\section{Budweiser moderniza anúncios machistas dos anos 50 para Dia Internacional da Mulher \\ Sai a dona de casa figurante que faz o jantar para o marido, entra a mulher independente que só quer beber sua cervejinha em paz.}

Fonte: https://www.huffpostbrasil.com

Neste caso, optando pelo verbo "modernizar", o título traz consigo uma carga positiva para a ação empreendida pela empresa que busca acompanhar os novos tempos. Contudo, ao também informar que esta ação foi desenvolvida especialmente para a 
comemoração do Dia Internacional da Mulher, o título parece sugerir o caráter oportunista da campanha.

Já no lead há uma cena em que a "dona de casa figurante" dos anos 50/60 dá lugar à "mulher independente" da atualidade, a partir da qual é possível observar as mudanças históricas e ideológicas ocorridas na sociedade. Nesse caso, diferente do exemplo anterior, enfatiza-se a mulher, seu dia, sua história e suas conquistas. O último exemplo é o seguinte, publicado pelo jornal $O$ Globo.

Figura 12 - Título e lead de reportagem do jornal $O$ Globo

\section{Fabricante de cerveja recria anúncios dos anos 1950 e 1960 sob ótica feminista}

Budweiser adapta campanhas clássicas para os dias de hoje, retirando o cunho machista típico da época

Fonte: https://oglobo.globo.com

Diferente dos exemplos anteriores, esta reportagem traz, explicitamente, tanto no título quanto no lead, os termos opositores "feminista" e "machista". No título, aponta-se que os anúncios foram recriados sob a "ótica feminista", sendo complementado pelo lead ao afirmar que as "campanhas clássicas" foram adaptadas para os dias atuais, tendo sido retirado "o cunho machista" que seria aceitável naquele contexto. Assim, o foco parece estar voltado para a ideia de reconfiguração da sociedade, à qual a empresa busca se adequar.

Nos três exemplos, é possível afirmar que as reportagens parecem querer indicar que a campanha da empresa aponta para uma concepção de que o machismo é algo do passado e que a atualidade é feminista. Sendo assim, vejamos, a seguir, quais modificações foram realizadas em três pares de anúncios, dispostos por ordem de publicação da versão original, a fim de discutirmos em que medida essa campanha pode (não) ser considerada positiva para as discussões acerca da equanimidade de gêneros na sociedade contemporânea. 
Figura 13 - Anúncio de 1956

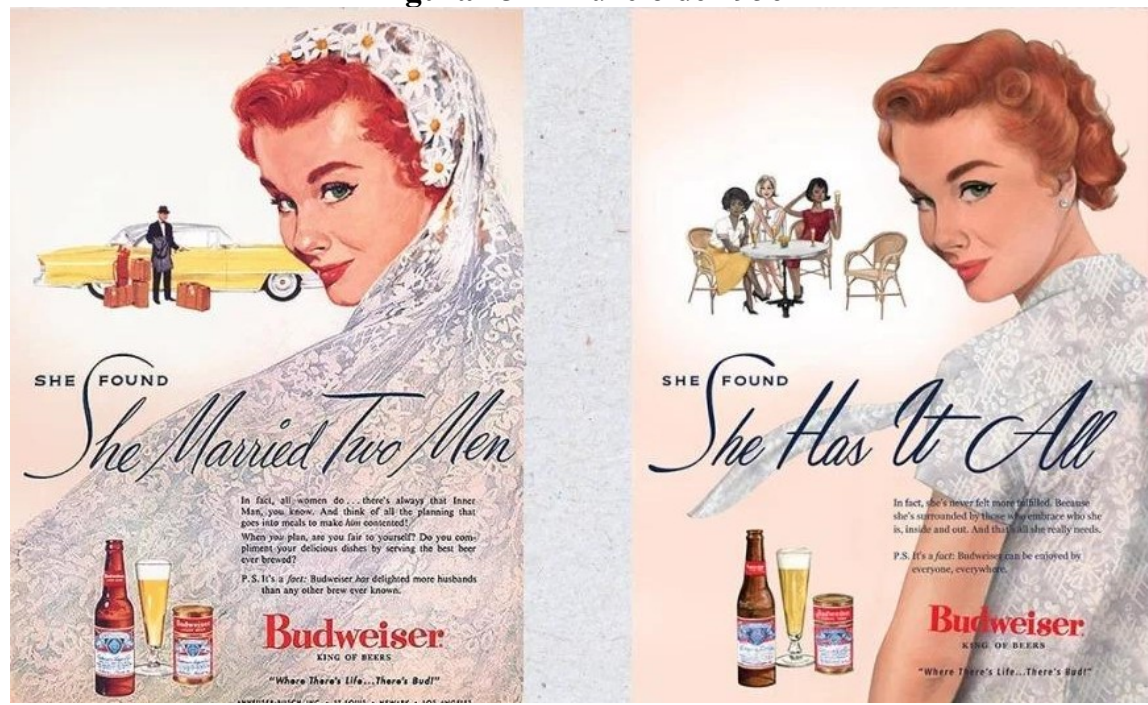

Fonte: https://exame.abril.com.br

Como pode ser observado, na recriação deste anúncio (Fig. 1), ${ }^{3}$ houve modificações tanto do texto verbal quanto do imagético. Assim, onde se lia "Ela descobriu que casou com dois homens", passou a ler-se "Ela descobriu que tem tudo que precisa", referindo-se às amigas sentadas em uma mesa ao fundo da imagem. Desse modo, a mulher de véu que compunha o anúncio com um marido à sua espera deu lugar a outra, com vestimenta sem menção ao casamento, que estaria em um encontro casual com amigas.

Nos anos 50, "ser mãe, esposa e dona de casa era considerado o destino natural das mulheres. Na ideologia dos Anos Dourados, maternidade, casamento e dedicação ao lar faziam parte da essência feminina; sem história, sem possibilidades de contestação" (BASSANEZI, 2004, p. 609). Percebemos, assim, como os valores e as crenças de uma época, ou seja, suas ideologias, podem influenciar a maneira como entendemos nosso lugar no mundo.

Para Fairclough (2001), a ideologia está intimamente ligada às relações de poder reveladas pelas práticas sociais instauradas na sociedade de modo a reverberar

\footnotetext{
${ }^{3}$ Porção limitada de material protegido por direitos autorais pode ser usado quando consistir em uso justo. De acordo com a Seção 107 da Lei de Direitos Autorais dos EUA, país onde as peças publicitárias circularam, "o uso justo de uma obra protegida por direitos autorais, incluindo o uso por reprodução em cópias ou fonogramas ou por qualquer outro meio especificado por essa seção, para fins como crítica, comentário, reportagem de notícias, ensino (incluindo várias cópias para uso em sala de aula), bolsa de estudos ou pesquisa não é uma violação de direitos autorais" (USCO, 2016, p. 19). Mesmo assim, reconhecemos a $\mathrm{AB}$ InBev como detentora dos direitos autorais das peças publicitárias analisadas neste artigo (Fig. 13, 14 e 15).
} 
convenções a ponto de que estas se naturalizem, como é o caso do discurso de que o destino feminino é o matrimônio e os cuidados do lar. Tendo em vista que as práticas discursivas tanto "contribuem para reproduzir (...) identidades sociais, relações sociais, sistemas de conhecimento e crenças" como também podem contribuir para transformálas (FAIRCLOUGH, 2001, p. 92), cabe-nos, ao analisar textos como estes anúncios, buscar compreender, por meio dos elementos verbais e imagéticos, como indivíduos, relações e ideias são constituídos pelo discurso.

Em relação à natureza dos eventos apresentados nos dois anúncios, em termos representacionais, podemos destacar a narrativa estabelecida por um processo de reação, a partir do qual a mulher é representada fitando o/a observador/a (criando uma certa cumplicidade) ao mesmo tempo em que também é objeto do olhar das amigas, dando, assim, destaque para o valor das relações de amizade. Em termos de significados interativos, representado em plano médio, o distanciamento social transparece uma sociabilidade reforçada pelo contato de demanda estabelecido. Isso, somado ao ângulo oblíquo empregado, sugere um ar de convite à contemplação dos outros elementos que compõem o anúncio e se inter-relacionam com esta participante em evidência.

Em termos composicionais, é pertinente observar que a participante principal deste processo de reação está disposta do lado direito, configurando uma informação nova que pode ser entendida, na primeira versão, como o casamento e mudança de vida, e na segunda versão, principalmente quando comparada à primeira, como uma atitude possível nesta nova configuração social.

O segundo par de anúncios analisado (Fig. 14), que teve sua versão original publicada em 1958, evidencia outra questão social: a subserviência da mulher em relação ao homem. 
Figura 14 - Anúncio de 1958

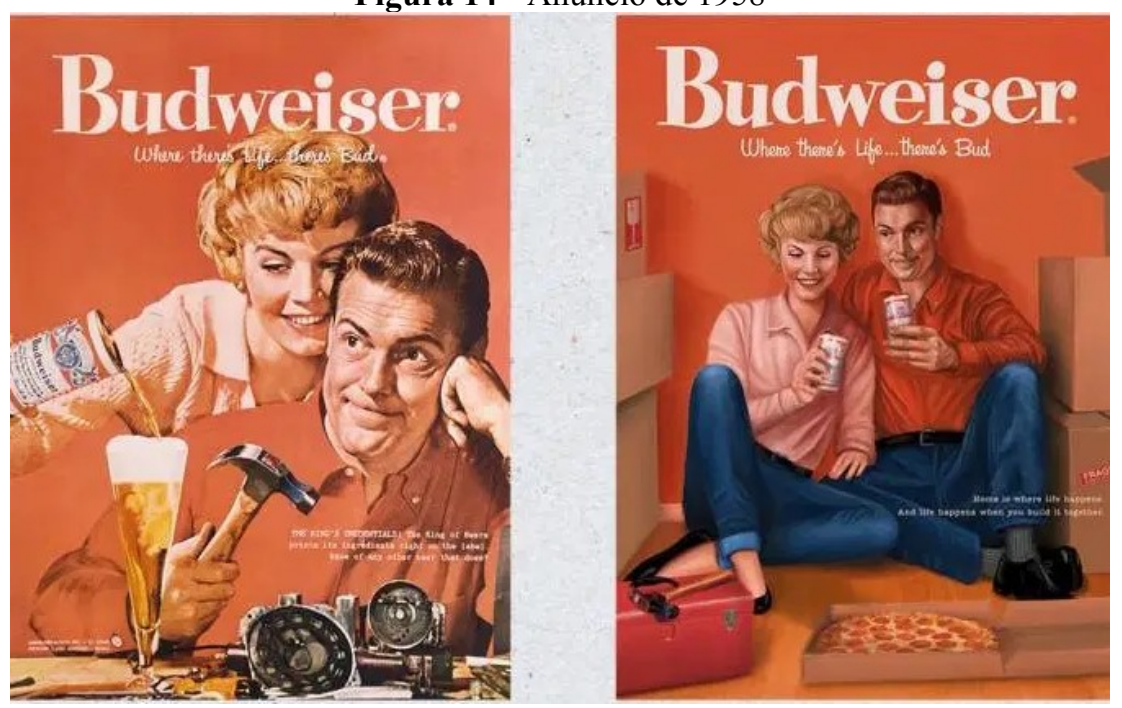

Fonte: https://exame.abril.com.br

Vejamos que, nas duas versões deste anúncio, há a frase “Onde há vida, há Bud”, porém, apesar de trazer o mesmo enunciado verbal, em se tratando de um texto multimodal, faz-se necessário atentar para as imagens que se relacionam com o texto, uma vez que, de acordo com Nascimento, Bezerra e Heberle (2011, p. 532),

\footnotetext{
As imagens, assim como a linguagem verbal, devem ser entendidas enquanto um sistema semiótico, ou seja, um conjunto de signos socialmente compartilhados e regidos por determinados princípios e regularidades, que utilizamos para representar nossas experiências e negociar nossa relação com os outros.
}

Em sala de aula, tendo em vista as teorizações da GDV sobre a leitura de elementos visuais, o/a professor/a pode orientar os/as alunos/as na percepção de que, em relação aos seus significados representacionais, as duas imagens apresentam um representação narrativa, a partir da qual se estabelece um processo de reação, cujo vetor é formado pelo olhar do personagem feminino em relação à cerveja, que, no primeiro anúncio, pertence ao personagem masculino, e, no segundo, pertence a ela. Já o personagem masculino é também reagente, porém o objeto de contemplação não é identificado em ambas versões, configurando processos de reação não-transacionais. Além disso, na primeira versão, apenas o homem parece estar fazendo alguma atividade relevante, ao passo que a mulher só lhe serve a cerveja, estampando satisfação em fazêlo e certa sensualidade ao aproximar seu corpo do dele. Na segunda versão, contudo, a 
mulher e homem parecem estar em intervalo de uma mesma ação, estando provavelmente envolvidos em mudança de casa, com seus objetos empacotados em caixas.

Já no que diz respeito aos significados interativos, nas duas imagens, há contato de oferta, uma vez que não se estabelece uma relação entre observador/a e participantes; a distância social, na primeira, encontra-se em plano médio, ao passo que estão representados em plano aberto na segunda versão, destacando diferentes graus de (im)pessoalidade com os/as leitores/as.

Finalmente, em relação aos seus significados composicionais, podemos dizer que nas imagens há uma marcante diferença: a posição da mulher em relação ao homem. $\mathrm{Na}$ primeira versão, a mulher aparece atrás do homem, que está sendo servido por ela enquanto trabalha. Já na segunda versão, os dois personagens estão dispostos lado a lado, bebendo cerveja enquanto descansam, apontando para uma relação mais equânime. Percebemos, assim, a flexibilização do papel da mulher, antes tida como uma figura subserviente ao homem, ideia que possui raízes que vão além dos discursos e sermões religiosos, sendo resultado de elementos sociais e culturais que remontam de antes da Idade Média (PIRES, 2016).

É possível compreender, portanto, que, ao aliar à leitura os estudos provenientes de outras áreas do conhecimento, p. ex. História, neste caso, pode-se conduzir os/as alunos/as a compreender que estes anúncios refletem muito mais que um recorte das lutas de poder em relações de gênero ocorridas entre os anos 1950-2000. Tal criticidade pode nos permitir desenvolver em sala de aula práticas de multiletramentos que estimulem posturas mais conscientes sobre nosso lugar em sociedade a partir de uma perspectiva emancipatória capaz de gerar efetivas mudanças sociais (MEURER, 2005).

O terceiro e último par de anúncios (Fig. 15) tem uma proposta similar a este segundo, mas apresenta um diferencial no tocante às relações possíveis na vida da mulher. 
Figura 15 - Anúncio de 1962

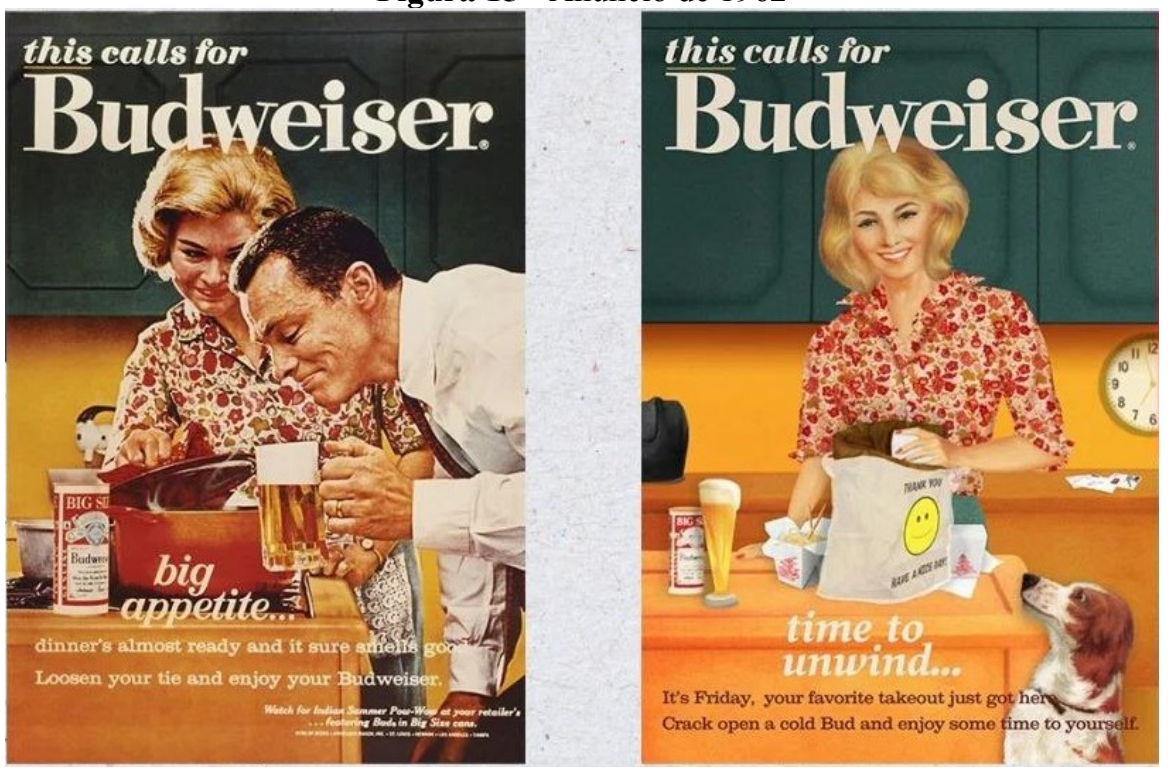

Fonte: https://exame.abril.com.br

$\mathrm{Na}$ versão original deste anúncio, estão representados dois atores num processo narrativo transacional: uma mulher, que remove parcialmente a tampa da panela para revelar seu conteúdo, e um homem, que segura uma cerveja e se inclina para sentir o aroma da comida. Já na segunda versão, a figura masculina dá lugar a um animal de estimação (cachorro), que configura outro tipo de companhia e relação com a participante agora principal.

Em relação à metafunção interativa, cabe observar que o olhar da mulher, que antes era direcionado ao participante masculino na imagem, passa a fitar o/a observador/a em contato de demanda, gerando maior envolvimento entre participante e observador/a. Em termos composicionais, faz-se necessário atentar para a mudança de plano em que a mulher é representada: antes em segundo plano, com parte do rosto sendo coberto pelo participante masculino posicionado à sua frente; agora, ocupando lugar de protagonismo.

A reconfiguração deste anúncio, assim como do segundo par analisado, põe em evidência a mudança pela qual a sociedade tem passado nas últimas seis décadas, a partir do questionamento de ideologias vigentes e do enfrentamento de concepções hegemônicas sobre relações de gênero. Ao discutir tais mudanças em sala de aula, podemos planejar práticas interdisciplinares. Por exemplo, professores/as de línguas podem desenvolver projetos com professores/as de História para problematizarem momentos históricos aos quais cada imagem se refere, especialmente quando 
consideramos que avanços e permanências também se relacionam com diferentes atravessamentos ideológicos, bem como questões culturais, políticas e econômicas.

No entanto, em oposição ao título da reportagem na Figura 10, fica evidente que uma campanha não pode "corrigir" um passado machista apenas produzindo outras peças publicitárias que parecem refletir certas mudanças nesse espaço temporal acerca do lugar das mulheres na sociedade. Há a necessidade de real engajamento com ações efetivas para o avanço de pautas feministas, por exemplo, no espaço das relações de trabalho, visto que relações de poder assimétricas e hegemônicas só podem ser efetivamente superadas a partir de reformulações nos próprios sistemas de opressão. A esse respeito, cabe destaque para o fato de que, dos dezoito membros que compõem o time de lideranças da AnheuserBusch InBev, ${ }^{4}$ apenas um deles é mulher. Não deveria a equidade de gênero também estar presente na distribuição mais equilibrada dos mais altos cargos da empresa entre homens e mulheres?

Por fim, acreditamos ser essencial destacarmos algumas questões que tais anúncios negligenciaram em suas duas versões, apontando para um silenciamento, gerado por questões estruturais mais profundas, que parece não ter sido minimamente superado nas últimas seis décadas. É igualmente notável e preocupante o fato de que não há qualquer diversidade de raça, etnia, classe social ou sexualidade - para citar apenas alguns marcadores sociais da diferença - nos anúncios analisados. Afinal, os/as consumidores/as de cerveja são apenas homens e mulheres cis, héteros, brancos/as e de classe média? Percebemos, assim, apagamentos de importantes aspectos de interseccionalidade (AKOTIRENE, 2019; COLLINS; BILGE, 2016) nesses anúncios, apontando para a urgência dessa problematização também no contexto escolar.

\section{Considerações finais}

Esperamos ter contribuído para a reflexão acerca da relevância do trabalho com o gênero anúncio em sala de aula, com ênfase na problematização de questões sociais complexas que estão por trás dos discursos que compõem estes textos e a sociedade em que circulam.

\footnotetext{
${ }^{4}$ Esta informação pode ser verificada no site da empresa. Disponível em: https://www.ab-inbev.com/whowe-are/people.html. Acesso em 25 set. 2020.
} 
Ao fornecermos exemplos de análise, buscamos elucidar como a leitura deste gênero pode ser mediada durante uma aula ou sequência de aulas, a partir do resgate e da aplicação de teorias que respaldam as reflexões e oferecem um norte para o delineamento de encaminhamentos metodológicos adequados à discussão de questões que vão desde a seleção de elementos linguísticos que compõem os enunciados verbais, à constituição das estruturas visuais, perpassados por discursos e ideologias.

Em se tratando do ambiente escolar, e, particularmente, do fazer docente com vistas ao desenvolvimento de um processo de ensino-aprendizagem dinâmico, a partir do qual os/as alunos/as tenham vez e voz, reiteramos a importância de cuidadoso planejamento, bem como da necessidade de constante busca por atualização e manutenção dos estudos por parte dos/as docentes. Além disso, reforçamos o quão benéfico e produtivo tende a ser o trabalho em conjunto, de modo cooperativo entre docentes de diferentes disciplinas escolares.

Acreditamos, por fim, que tais reflexões podem contribuir para o desenvolvimento e o fortalecimento do ensino de leitura crítica nas escolas, por meio de práticas de multiletramentos, em um contexto educacional que tenha como princípio norteador a formação de alunos/as capazes de atuar em sociedade de maneira competente, responsável e saudável nos âmbitos cognitivo, físico, emocional e social.

\section{Contribuição}

Maria Vanessa Monteiro das Chagas: Conceptualização, Curadoria de dados, Análise formal, Investigação, Metodologia, Administração do projeto, Visualização, Escrita rascunho original e Escrita - análise e edição; Fábio Alexandre Silva Bezerra: Conceptualização, Análise formal, Investigação, Metodologia, Supervisão, Visualização, Escrita - rascunho original e Escrita - análise e edição.

\section{Referências}

AKOTIRENE, C. Interseccionalidade. São Paulo: Sueli Carneiro; Pólen, 2019.

BASSANEZI, C. Mulheres nos Anos Dourados. In: PRIORE, M. (org.); BASSANEZI, Carla (coord. de textos) História das mulheres no Brasil. 7 ed. São Paulo: Contexto, 2004. 
BEZERRA, F. A análise crítica do discurso e os multiletramentos: o papel da linguagem no fazer docente contemporâneo. In: NÓBREGA, C.; ARCOVERDE, R.; BRANCO, S.; FARIAS, W. (org.) Educação linguística e literária: discursos, políticas e práticas. Campina Grande: UFCG, 2016. p. 189-204.

BONIFÁCIO, C. O uso da Gramática do Design Visual nas aulas de leitura no ensino de língua portuguesa. In: MELO, C.; SALES, L.; SANTOS, L.; SILVA, M. (org.) Linguagem, educação e tecnologias: implicações para o ensino. João Pessoa: Editora da UFPB, 2013. p. 217-243.

BRASIL. Parâmetros Curriculares Nacionais. Brasília: MEC/SEF, 1998.

BRASIL. Orientações curriculares para o ensino médio. Secretaria de Educação Básica. Brasília: MEC/SEB, 2006.

BRASIL. Base Nacional Comum Curricular (BNCC). Brasília: MEC, 2018.

COLLINS, P. H.; BILGE, S. Intersectionality. Cambridge, Malden: Polity Press, 2016.

FAIRCLOUGH, N. Language and power. 3 ed. Londres, Nova York: Longman, 2015[1989].

FAIRCLOUGH, N. Discourse and social change. Londres: Longman, 2001.

KLEIMAN, A. Agenda de pesquisa e ação em linguística aplicada: problematizações. In: MOITA LOPES, L. P. (org.). Linguística aplicada na modernidade recente: Festschrift para Antonieta Celani. São Paulo: Parábola Editorial, 2013. p. 39-58.

KRESS, G.; VAN LEEUWEN, T. Reading images: the grammar of visual design. 2. ed. Londres, Nova York: Routledge, 2006.

MEURER, J. L. Gêneros textuais na análise crítica de Fairclough. In: MEURER, J. L.; BONINI, A.; MOTTA-ROTH, D. (org.) Gêneros: teorias, métodos, debates. São Paulo: Parábola Editorial, 2005. p. 81-106.

MOITA LOPES, L. P. Linguística aplicada e vida contemporânea: problematização dos construtos que têm orientado a pesquisa. In: MOITA LOPES, Luiz Paulo da (org.) Por uma linguística aplicada indisciplinar. São Paulo: Parábola Editorial, 2006. p. 85-107.

NASCIMENTO, R.; BEZERRA, F.; HEBERLE, V. Multiletramentos: iniciação à análise de imagens. Linguagem e Ensino, v. 14, n. 2, 2011.

PIRES, J. D. A. Misoginia medieval: a construção da justificação da subserviência feminina a partir de Eva e do pecado original. Faces da História. v. 3, n. 1, 2016. 
ROJO, R. Letramentos múltiplos, escola e inclusão social. São Paulo: Parábola Editorial, 2009.

Recebido em: 16 de setembro de 2020 Aceito em: 05 de março de 2021 Publicado em maio de 2021

Maria Vanessa Monteiro das Chagas

E-mail: vanessachagasm@gmail.com

ORCID: https://orcid.org/0000-0002-9951-5623

Fábio Alexandre Silva Bezerra

E-mail: fabes10@yahoo.com.br

ORCID: https://orcid.org/0000-0002-3383-0188 